\title{
A gestão escolar na promoção da inovação pedagógica: percepções de pesquisadores em educação
}

Josiane Carolina Soares Ramos Procasko, Instituto Federal de Educação, Ciência e Tecnologia do Rio Grande do Sul - Campus Porto Alegre/IFRS-POA, josiane.ramos@ @oa.ifrs.edu.br, https://orcid.org/0000-0001-7223-6889

Lucia Maria Martins Giraffa, Programa de Pós-Graduação em Educação Pontifícia Universidade Católica do Rio Grande do Sul - PUCRS, giraffa@pucrs.br, https://orcid.org/0000-0001-8062-3483

Resumo: Costuma-se focar a questão da inovação pedagógica e do atendimento das emergências contemporâneas na formação docente, já que estes sujeitos são os principais agentes de mudanças e não temos dúvida disso. No entanto, todo projeto de inovação e transformação necessita de ações sincronizadas e apoiadas em intervenções concretas e afirmativas por parte da gestão. Neste relato de experiência apresentamos algumas provocações referentes aos desafios da prática gestora no contexto das tecnologias digitais em processos de inovação nas instituições educacionais. Busca-se ampliar a discussão da inovação de práticas pedagógicas na perspectiva da parceria da ação gestora, buscando elementos adicionais para as discussões realizamos uma pesquisa com grupo focal envolvendo mestrandos e doutorandos de um Programa de Pós-Graduação stricto sensu em Educação.

Palavras-chave: gestão educacional; inovação pedagógica; formação docente.

\section{School management in promoting pedagogical innovation: perceptions of education researchers}

\begin{abstract}
It is customary to focus on the issue of pedagogical innovation and the care of contemporary emergencies in teacher education, since these subjects are the main agents of change and we have no doubt about that. However, every innovation and transformation project needs synchronized actions and supported by concrete and affirmative interventions by management. In this experience report, we present some provocations regarding the challenges of management practice in the context of digital technologies in innovation processes in educational institutions. We seek to broaden the discussion on the innovation of pedagogical practices in the perspective of the partnership of management action, seeking additional elements for the discussions. We conducted a research with a focus group involving masters and doctoral students from a stricto sensu Graduate Program in Education.
\end{abstract}


Keywords: educational management; pedagogical innovation; teacher education.

\section{Introdução}

Segundo Gómez (2015), a seleção das competências básicas a serem desenvolvidas na contemporaneidade está atrelada aos valores considerados essenciais de cada comunidade para seus cidadãos. Gómez percebe esta relação a partir do seu olhar sobre a escola e o currículo nela implementado, como uma possibilidade (e potência) no processo de desenvolvimento do sujeito, de forma singular, a construir seu próprio projeto de vida pessoal, social e profissional, onde consiga "percorrer o seu próprio caminho da informação ao conhecimento e do conhecimento à sabedoria" ( $\mathrm{p}$. 76). Portanto, para Gómez (2015), algumas competências básicas devem ser desenvolvidas nesse espaço, como a capacidade de utilizar e comunicar o conhecimento construído historicamente; a capacidade para viver e conviver democraticamente em grupos cada vez mais heterogêneos; e a capacidade de viver a atuar autonomamente na sua vida.

Dessa forma, a tecnologia além de ser um importante elemento, acaba tornando-se um produto de uma sociedade e de uma cultura, como aponta Lévy (2009), algo indissolúvel às atividades humanas. Castells (2002, p. 43) concorda com essa ideia, ao compreender a tecnologia como um elemento da sociedade, já que a mesma não pode ser entendida ou representada sem suas ferramentas tecnológicas. Na tecnologia as relações são criadas a partir de inúmeros atores humanos que inventam, produzem e interpretam de diferentes formas as técnicas (CASTELLS, 2002). Essas relações situamse na rede e consequentemente estão vinculadas à dualidade presente no movimento da globalização. Por um lado, observamos uma grande concentração de riquezas (poder e capital), e de outro, principalmente com o advento da Web 2.0, um crescimento significativo do movimento coletivo e colaborativo.

A superação de um modelo de escola tradicional weberiano é um processo árduo e moroso, pois prescinde a cultura histórica construída em detrimento de algo não conhecido, pautado pelo atual paradigma de transição no qual vivemos, gerando insegurança, descontentamento e resistência por parte dos sujeitos. Grande parte dos docentes atuantes na escola não possui ainda formação adequada para lidar com essas novas características culturais do mundo digital. A escola, os docentes e os discentes estão muitas vezes em caminhos divergentes no que diz respeito ao processo pedagógico, muitos esforços, discussões, projetos e ações tem se desenvolvido para diminuir a brecha na formação docente. Neste artigo vamos refletir acerca de um aspecto que impacta sobremaneira a ação docente relacionada a inovação de práticas pedagógicas e, que ao nosso ver, muitas vezes não é considerada como deveria: o entendimento deste novo contexto e o apoio/percepção dos gestores escolares para fomentar a cultura da mudança e a inovação pedagógica.

\section{A gestão educacional e os imperativos da cibercultura}

Vivemos em um período de transição, onde ainda existe uma distância bastante grande entre a necessidade do mundo e da cultura digital e a realidade das instituições 
educacionais. Os discentes possuem determinadas características e necessidades que o docente não consegue atender, pois não obteve durante sua vida profissional formação específica para tal situação. Mediando e organizando esse processo discente-docente temos a equipe responsável pela gestão escolar. Esse grupo, Diretor(a), Vice-Diretor(a) e Coordenador(a) Pedagógico(a), muitas vezes é esquecido nos processos formativos viabilizados pelos Sistemas de Ensino no que diz respeito ao mundo digital. Consequentemente, não são estimulados a refletir sobre sua práxis educativa enquanto líderes escolares, não incentivando mudanças necessárias frente aos imperativos da cibercultura. Esta lacuna de informação/reflexão pode impactar negativamente $o$ processo de mudança e inovação no ecossistema escolar, uma vez que ações propostas por docentes podem não ser devidamente compreendidas e apoiadas.

Para Lück (2011), existe um conjunto de fatores, construídos ao longo da história institucional que influenciam as escolas: padrões de autoridade e estilos de liderança; relações interpessoais e de poder praticados; valores e crenças propagados e assumidos; estilos de comunicação e relacionamento interpessoal adotados; as formas de organização, distribuição e implementação do trabalho; as reações dos grupos diante dos desafios; as reações às influências externas (por exemplo as determinações das mantenedoras e do sistema educacional); as reações às influências internas (por exemplo as condições materiais de trabalho); os recursos disponibilizados; o nível de formação/capacitação das pessoas e sua orientação profissional; o tamanho da escola, entre outros.

Gestores e comunidade escolar precisam construir uma mesma identidade organizacional, disseminando as mesmas ideias, isto não é tarefa específica dos docentes. A transformação digital deve facilitar a comunicação, a transparência e a colaboração, desenvolvendo o engajamento de todos nos processos educacionais, construindo novas competências digitais para atender os desafios apresentados nesse contexto de cibercultura. Para intervirmos nos processos da cultura organizacional escolar, precisamos considerar os processos de aprendizado organizacional para além das formas tradicionais de ensino. Devemos levar em consideração o ambiente informal vivenciado e a aprendizagem que ocorre cotidianamente em diferentes níveis.

Devem ser fomentadas nesse processo a identificação dos agentes de mudança, uma comunicação acessível, a visibilidade de projetos já alcançados e os benefícios produzidos, o investimento na formação de competências digitais de todos os envolvidos no processo educacional, a proposição de um plano de acompanhamento do processo de mudança, a fim de reavaliar as ações, além da promoção da colaboração da comunidade escolar na construção de novos conhecimentos. Investe-se na organização de formações para desenvolvimento acadêmico em serviço, reorganização curricular na formação de base (graduação) e nos processos formativos em nível de pós-graduação buscando promover a "mudança" desejada e, no entanto, sem o apoio de uma gestão com visão integrada e inovadora afim de que o ecossistema escolar seja efetivamente um espaço integrado de ações que promovam inovação, os objetivos não serão alcançados.

\section{Material e Métodos}


Muito se discute e investe na questão da necessidade de mudar o processo de formação docente buscando que estas mudanças reverberem positivamente no fazer docente de forma contextualizada e em sintonia om todos agentes que compõem o ecossistema escolar (gestores, docentes, discentes, colaboradores e família). Ao nosso ver a formação dos gestores educacionais também deveria contemplar tais aspectos especialmente no que tange a compreensão das implicações de tais mudanças para os processos de gestão. Assim sendo, emergem algumas inquietações: Estariam os gestores que atuam na rede escolar (em qualquer nível) aptos a compreenderem e apoiarem, de maneira ampla as mudanças emergenciais que postulam a comunidade de pesquisa em Educação? Qual seria a percepção dos docentes acerca dos gestores escolares no que tange ao acolhimento e compreensão deste contexto mutante e instigante que vivemos? Acreditamos que estes questionamentos nos levaram (e levam) a trilhar muitas frentes de investigações que ora se iniciam.

Em função da natureza deste estudo, utilizamos abordagem qualitativa, dentro de uma perspectiva exploratória-investigativa, a fim de compreender inicialmente as concepções dos docentes acerca do papel/parceria necessária relacionadas ao "fazer gestionário" versus o fazer docente no espaço educativo. No sentido de contemplar vários cenários possíveis para esta interlocução, buscamos a opinião de estudantes de uma Programa de Pós-Graduação em Educação stricto sensu, sobre seu entendimento da gestão de processos educacionais para construção de um espaço de fomento à inovação pedagógica. A coleta de dados apoiou-se na aplicação de um questionário com questões abertas e fechadas, além da realização de um grupo focal com os mestrandos e doutorandos participantes da pesquisa. Foi aplicado um questionário on-line com auxílio da ferramenta Google Forms para a caracterização dos participantes da pesquisa. Ao todo participaram da investigação 12 (doze) estudantes-pesquisadores, onde responderam questões gerais sobre a sua formação (caraterização do grupo) e outras relacionadas ao seu nível de fluência digital, sua atuação (ou não) na gestão educacional, a esfera da instituição onde sua experiência em gestão se deu, e por fim, o maior desafio de um gestor na atualidade. A escolha desses sujeitos se deu a partir de características comuns, especialmente aquelas relacionadas ao seu interesse no aprofundamento de seus estudos na área de Educação e Tecnologias, qualificando-os para o desenvolvimento da discussão em estudo.

Em um momento posterior, os sujeitos da pesquisa participaram de um grupo focal (GATTI, 2005), para aprofundarmos questões emergentes do questionário aplicado anteriormente. Escolhemos a técnica do grupo focal de forma complementar aos dados produzidos pelo questionário aplicado. Pois o grupo focal nos permitiu perceber uma série de processos de construção da realidade, e como afirma Gatti (2005), dentro de um apanhado de conhecimento de representações, percepções, crenças, hábitos, valores, restrições, preconceitos, linguagens e simbologias, relevantes para o tema investigado. No grupo focal, a discussão centrou-se na temática "A gestão educacional para a inovação no ambiente escolar", a mediação do processo foi realizada por outros cinco estudantes de pós-graduação (moderadores dos grupos).

$\mathrm{Na}$ análise dos dados, utilizamos a técnica de análise de conteúdo, com foco na análise categorial, considerando a "totalidade de um texto, passando-o pelo crivo da classificação e do recenseamento, segundo a frequência de presença (ou de ausência) de itens de sentido", como aponta Bardin (2016, p. 43). A partir da exploração do corpus 
da pesquisa, constituído pelos instrumentos de coleta de dados, foram definidas as categorias com as suas respectivas unidades de registro, objetivando "descobrir os núcleos de sentido que compõem a comunicação e cuja presença, ou frequência de aparição, pode significar alguma coisa para o objeto analítico escolhido" (Bardin, 2016, p. 135). A gestão da análise dos dados das entrevistas foi realizada pelo software Atlas.ti, empregado para organizar sistematicamente fatos complexos em dados não estruturados.

\section{Resultados e Discussão}

Durante o processo de análise dos dados percebemos que neste complexo formado pela interação entre Educação, Formação e Tecnologia, se estabelecem processos de carácter intrínseco (endógenos) e extrínsecos (exógenos), que se retroalimentam e estão em constante movimento, se levarmos em consideração às profundas mudanças que o campo educativo vem sofrendo especialmente no início do século XX com a dinamização dos processos de gestão (GETALLI; MARQUEZAN, 2013), às demandas de formação advindas do avanço tecnológico e os novos modos de "ser, estar e fazer" no mundo digital (NASCIMENTO, 2012).

Esta perspectiva de trabalho nos possibilitou, em alguma medida, compreender - no conjunto do grupo estudado - a gestão da educação a partir da sua materialização na vivência/experiência dos sujeitos, e ainda os elementos balizadores que compõem a sua prática. Desta forma, conseguimos identificar como dimensões de reconhecimento dos processos de gestão da educação, 4 (quatro) dimensões emergentes neste contexto. Fica claro, ao analisarmos os dados que a gestão da educação se manifesta (na percepção dos sujeitos da pesquisa) de forma articulada a categorias clássicas do campo disciplinar da administração: Gestão de Pessoas, Gestão de Recursos, Gestão da Informação e a Gestão da Inovação.

A Gestão de Pessoas se apresenta como sendo o elemento que busca evocar o relacionamento entre as pessoas em busca dos objetivos das organizações e dos indivíduos (CHIAVENATO, 2009), ou seja, é a junção de atitudes e métodos, técnicas e práticas pré-definidas, que buscam gerenciar comportamentos internos e potencializar o recurso humano na busca por objetivos comuns. Aqui nos referimos ao fortalecimento do engajamento do grupo, das relações interpessoais, da mediação de conflitos, da avaliação de processos, da visão sistêmica, entre outros.

A Gestão de Recursos surge sob uma perspectiva próxima ao modelo institucional de gestão financeira (ALMEIDA; KELLER-FRANCO, 2016), porém no estudo aqui apresentado, fica evidente que ao falarem em "recursos" há uma referência direta ao conjunto de estruturas que dão suporte aos processos de gestão, desde infraestrutura do espaço escolar, passando pelas tecnologias da informação e comunicação que otimizem o trabalho na escola, até mesmo a disponibilidade de pessoas no quadro de funcionários para o atendimento às demandas da escola.

A Gestão da Informação por sua vez, desvela um ciclo de atividade da rotina organizacional de uma instituição. Podemos traduzir essa rotina como um processo de organização orientada ao conhecimento. Significa empregar o recurso, saber para aumentar a eficiência e renovar a qualidade, gerando saberes com base nas informações 
e transformando-os em vantagens competitivas sustentáveis, que chegarão a ser mensuráveis como êxitos em suas atividades (NORTH, 2010).

Já a Gestão da Inovação emerge como um elemento de construção de novos saberes para a transformação do ambiente educacional na contemporaneidade, pois a inovação acaba evidenciando a necessidade de desinstalação do paradigma fabril dentro da gestão da escola (BRANDÃO, 2005). O conceito de inovação é polissêmico, próprio e característico dos distintos campos disciplinares do saber, porém a compressão de Gómez (2000), busca uma espécie de "unidade" onde a inovação se efetiva a partir de uma modificação praticada de maneira deliberada dentro de um sistema, que objetiva melhorias ou mesmo aperfeiçoamento de algum aspecto estrutural presente nas dimensões sociais.

Tendo estas dimensões inseridas no contexto social de cibercultura, surge a necessidade das instituições educacionais, seus gestores e comunidade escolar utilizarem os conceitos e técnicas de Mineração de Dados Educacionais (MDE) e do Learning Analytics (LA) como potência para a efetivação das práticas gestionárias. Para Giraffa (2015, p. 36), a Mineração de Dados é uma subárea da Computação que apoia o gerenciamento do "grande volume de dados gerados por diferentes softwares integrados, provendo informações para que docentes e discentes possam tomar decisões relacionadas aos processos de ensinar e de aprender". E o Learning Analytics seria um campo de estudos emergente onde são utilizadas sofisticadas ferramentas analíticas para apoiar os processos de ensino e de aprendizagem.

As quatro dimensões que evidenciamos anteriormente (Gestão de Pessoas, Gestão de Recursos, Gestão da Informação e Gestão da Inovação) compõem, no seu conjunto, a percepção dos processos, práticas e desafios da gestão educacional. Porém a complexidade do campo, exige de nossa parte outros elementos de igual importância nos processos, como um conjunto adjacente que circunda as dimensões citadas tanto de forma intrínseca (endógeno) quanto extrínseca (exógeno).

Como elementos endógenos temos, nas percepções dos sujeitos de pesquisa, 2 (dois) fatores: a formação acadêmica (inicial e continuada) do gestor e a sua relação com as tecnologias quando nos referimos às práticas gestionárias. A Formação Acadêmica é um importante elemento para se pensar no desenvolvimento/aplicação das práticas de gestão, pois como afirma Libâneo (2004), há uma relação íntima entre a formação dos sujeitos e a trajetória escolhida, no sentido de regular/orientar suas práticas. Já a tecnologia surge a partir da necessidade da (re)significação do papel e da função do gestor, a tecnologia se apresenta como uma importante ferramenta de otimização e dinamização do "fazer gestão" (ALMEIDA; ALONSO, 2007) na era digital.

Articulado aos elementos intrínsecos, temos elementos exógenos que representam movimentos importantes na implementação das lógicas de gestão da educação no contexto da cibercultura: A participação dos sujeitos e o planejamento da ação educativa. A participação dos sujeitos não pode ser traduzida apenas como a "simples consulta aos indivíduos", como aponta Flach (2012), este modelo não garante uma participação consciente. A participação aqui se mostra como um processo por meio do qual as diversas camadas têm oportunidade de contribuir na formação de planos coletivos, objetivando a intervenção na realidade social e histórica. Já o planejamento da 
ação educativa surge a partir do estabelecimento de metas e de objetivos que o espaço educativo deseja alcançar, é nesse espaço que o conhecimento sobre gestão se efetiva, ou seja, o planejamento é um importante processo de organização e coordenação, serve como ponte entre a atividade escolar e o contexto social e político natural do ambiente escolar (LÜCK, 2000).

A partir dos dados produzidos pelos instrumentos de pesquisa (questionário e grupo focal), percebemos que os processos de gestão se mostram dentro de uma complexidade tamanha, principalmente por optarmos pelo entendimento das percepções dos sujeitos de pesquisa, e seus diversificados contextos de atuação e vivência. A Gestão da Educação no contexto do estudo apresentado, tem 4 (quatro) grandes dimensões de percepção dos sujeitos de pesquisa. A Gestão da Educação se constitui a partir da Gestão de Pessoas, a Gestão de Recursos, a Gestão da Informação e a Gestão da Inovação, porém estas dimensões são interpenetradas por fatores endógenos que são intrínsecos aos processos, como a formação acadêmica dos gestores e a incorporação de tecnologias digitais nas práticas gestionárias. E como fatores exógenos aparecem nesse contexto de forma extrínseca a Gestão da Educação, a Participação dos Sujeitos frente aos processos de efetivação/articulação da Gestão Educacional, e ainda o Planejamento da Ação Educativa no contexto da Gestão da instituição de Ensino.

Os processos de Gestão da Educação no contexto da cibercultura, não pode ser reduzida apenas ao uso de tecnologias na implementação de práticas gestionárias no interior das unidades de ensino. Este processo se efetiva a partir da articulação de uma série de elementos/ações/práticas que possibilitem a percepção dos sujeitos frente às necessidades e às demandas a serem enfrentadas no mundo contemporâneo, onde a tecnologia é uma parte importante a ser assimilada, mas não é a única. A cibercultura, dessa forma, deixa de ser algo estático dirigido a um grupo de sujeitos específicos, e passa a incorporar a dinâmica social da escola, onde os diferentes sujeitos desta comunidade, tem em suas práticas cotidianas, elementos da cibercultura como a conectividade, a interatividade e a cooperação, como aponta Lévy (2009) em seus apontamentos.

\section{Conclusões}

Os resultados deste estudo possibilitaram-nos a organização e a articulação de quatro dimensões emergentes e reconhecidas pelos estudantes de pós-graduação sobre os processos de gestão da educação: Gestão de Pessoas, Gestão de Recursos, Gestão da Informação e Gestão da Inovação. Com o grupo focal, além de estimular a troca efetiva entre os participantes, introduzindo o assunto, e propondo algumas questões, foi garantido que os participantes se expressassem livremente, trazendo elementos relevantes que circundam de forma intrínseca e extrínseca às dimensões citadas anteriormente.

Como elementos endógenos foram reconhecidos a Formação Acadêmica (inicial e continuada) e a relação com as Tecnologias Educacionais como fatores relevantes para o gestor no mundo digital. O interesse e a formação constante mostramse como princípios centrais para a prática de gestão contemporânea. Como elementos exógenos foi reconhecido pelos pós-graduandos a relevância dos processos de Planejamento das ações educativas juntamente com a Participação ou colaboração dos 
envolvidos no processo para o sucesso das intervenções. Todos os elementos citados são fundamentais para uma prática gestora consciente da atual conjuntura que vivemos, eles devem dialogar com a cultura organizacional escolar, sofisticando cada vez mais os seus processos.

A gestão da educação se apresenta de forma imbricada nas concepções, vivências e experiências dos sujeitos da pesquisa, para além do "administrar". O avanço tecnológico e por conseguinte os processos que estamos imersos no contexto da cultura digital faz com que o ato de "gestar" seja (re)significado cotidianamente. As demandas sociais emergentes dessa cultura, faz com a implementação dos processos de gestão, sua articulação e sua execução não se pautem única e exclusivamente pelo paradigma educacional da "qualidade total", pelo contrário, as percepções dos pós-graduandos evidenciam que a própria noção da qualidade é substituída por uma qualidade social. A gestão educacional, abarca uma série de arranjos no interior das instituições de ensino que permita - por meio de uma prática gestora inclusiva, participativa e planejada - o reconhecimento dos sujeitos em um contexto onde as relações estão imersas na cultura digital.

Esses desafios da/na gestão despontam em distintos movimentos do espaço escolar, existe um importante movimento interno (individual) de sofisticação de pensar e agir na escola, passando pelos aspectos formativos, a experiência de atuação no campo, a concepção individual do papel da educação, chegando a dimensões estruturais da ação gestora, como o desenvolvimento do planejamento estratégico. Podemos apontar ainda a necessidade da ressignificação das práticas docentes a partir de elementos da cultura digital, onde a sofisticação que apontamos anteriormente vai tomando outros sentidos e consequentemente produzindo modelos de gestão.

Cabe considerar a emergência de uma formação de gestores que compreenda a complexidade deste mundo digital, impactada pela cultura digital e carente de uma educação digital que privilegie a construção de uma inteligência digital. Inteligência Digital esta, segundo Tibau (2016), é a soma das habilidades técnicas, mentais e sociais que permitem a um indivíduo encarar os desafios e se adaptar às demandas da vida digital. O contexto pandêmico acelerou de forma intensa e emergencial que a adoção da necessidade de uma formação mais ampla e inclusiva no aspecto da compreensão da cibercultura permitindo tomadas de decisão e gerência das intercorrências de um mundo amplamente conectado e simbiótico.

A inovação pedagógica transcende o espaço de ação docente e necessita de apoio e uma visão gestionária que permita a sincronicidade de ações e projetos em comum. Esta parceria deve buscar a formação de indivíduos capazes de serem agentes de transformação do tecido social num mundo marcado pela crescente desigualdade de oportunidades, cabe a nós, membros do ecossistema escolar, sincronizar as ações que efetivamente nos levem a construir um espaço de formação diferenciado e inclusivo.

\section{Referências}

ALMEIDA, M. E. B. de.; ALONSO, M., (Orgs.). Tecnologias na Formação e na Gestão Escolar. São Paulo: Avercamp, 2007. 
ALMEIDA, S. C.; KELLER-FRANCO, E. Administração dos Recursos Financeiros no Contexto da Gestão democrática. Revista de Administração Educacional. v. 1, no ${ }^{\circ}$, p. 17-35, jul./dez 2016. Disponível em: $<$ https://tinyurl.com/t3237nj>. Acesso em: 01 $\operatorname{dez} 2019$.

BARDIN, L. Análise de conteúdo. São Paulo: Edições 70, 2016.

BRANDÃO, Z. (Org). A crise dos paradigmas e a educação. 10. ed. São Paulo: Cortez. 2005.

CASTELLS, M. A sociedade em rede. v. 1, Economia, Sociedade e Cultura. 6. ed. São Paulo: Paz e Terra, 2002.

CHIAVENATO, I. Administração de Recursos Humanos: fundamentos básicos. $7^{\mathrm{a}}$ ed. Barueri, SP: Manoele, 2009.

FLACH, S. de. F. Contribuições para o Debate Sobre a Qualidade Social da Educação na Realidade Brasileira. Contexto e Educação. ano 27, nº 87, p. 4 - 25, Jan./Jun. 2012. Disponível em: $<$ https://tinyurl.com/vwjrfrv>. Acesso em $01 \mathrm{dez} 2019$.

GATTI, B. A. Grupo focal na pesquisa em ciências sociais e humanas. Brasília: Líber Livro, 2005.

GETALLI, L. D.; MARQUEZAN, L. I. P.; Contribuições da Gestão Escolar para a Qualidade da Educação. Regae: Rev. Gest. Aval. Educ. v. 2, n. 4, p. 43 - 62, jul/dez. 2013. Disponível em: < https://tinyurl.com/sjpf2m7>. Acesso em $03 \mathrm{dez} 2019$.

GIRAFFA, L. M. M. Recursos de Learning Analytics para Compor Indicadores Auxiliares na Avaliação dos Estudantes. EmRede, v. 2, n. 2, p. 32-43, 2015. Disponível em: < https://tinyurl.com/wc49ufg>. Acesso em: 01 dez 2019.

GÓMEZ, A I. P. A cultura escolar na sociedade neoliberal. Porto Alegre: Artmed, 2000 .

GÓMEZ, A I. P. Educação na era digital: a escola educativa. Porto Alegre: Penso, 2015.

LÉVY, P. Cibercultura. São Paulo: Editora 34, 2009.

LIBÂNEO, J. C. Organização e Gestão da Escola: teoria e prática. $5^{\text {a }}$ ed. Goiânia/GO - Editora Alternativa, 2004.

LÜCK, H. A Aplicação do Planejamento Estratégico na Escola. Gestão em Rede. n ${ }^{\circ}$. 19, p. 8 - 16, Abr/2000. Disponível em: $<$ https://tinyurl.com/yx79qfp3 $>$. Acesso em 01 $\operatorname{dez} 2019$.

LÜCK, H. Gestão da cultura e do clima organizacional da escola. 2. Ed. RJ: Vozes, 2011.

NASCIMENTO, C. F. V. do. Desafio docente: era (digital) da informatização. Revista Thema, v. 9, n. 2, 2012. Disponível em: $<$ https://tinyurl.com/ugabaho $>$. Acesso em 03 $\operatorname{dez} 2019$.

NORTH, K. Gestão do Conhecimento: um guia prático rumo à empresa inteligente. Rio de Janeiro: Qualitymark, 2010. 
TIBAU,M. Inteligência Digital. Updateordie.com. 2016. Disponivel em: < https://www.updateordie.com/2016/09/02/inteligencia-digital/ >. Acesso em 12 jul 2021. 